\title{
Two injections of erythropoietin correct moderate anemia in most patients awaiting orthopedic surgery
}

\author{
[Deux injections d'érythropoïétine corrigent une anémie modérée chez la plupart \\ des patients en attente d'une opération orthopédique]
}

Nadia Rosencher MD, ${ }^{*}$ Dominique Poisson MD, $†$ Aline Albi MD, ${ }^{*}$ Martine Aperce MD, $\ddagger$ Jeanne Barré MD, $\$$ Charles Marc Samama MD PhDI

Background: The primary objective of this study was to assess the number of erythropoietin (EPO) injections required to reach a hematocrit $(\mathrm{Ht})$ of $40 \%$ in moderately anemic patients. The secondary objective was to compare this strategy with autologous blood donation $(A B D)$ in elective orthopedic surgery in terms of red blood cell $(\mathrm{RBC})$ production.

Study design and methods: 93 patients with a baseline $\mathrm{Ht}$ between 30 and 39\% were randomized into two groups the day of the preoperative assessment. In the EPO group, patients received 40,000 UI/week SC until they reached a maximal Ht of $40 \%$. In the ABD group, a RBC pack was collected every week as long as the Ht was above $33 \%$.

Results: Two EPO injections were necessary to reach a $40 \% \mathrm{Ht}$ in $63 \%$ of the patients. It was possible to collect two RBC packs in $45 \%$ of the patients in the $\mathrm{ABD}$ group. Volume of $\mathrm{RBC}$ production was significantly higher in the EPO group: $268 \pm 142 \mathrm{~mL}$ vs I4I \pm 129 (P $=0.000 \mathrm{I}$ ). In the EPO group, Ht was significantly higher on days one and three after surgery and at discharge. The energy score was better in the EPO group. In the ABD group, $12.6 \%$ patients vs $6.5 \%$ in the EPO group received allogeneic transfusion (ns).

Conclusion: Only two EPO injections were sufficient to reach a $\mathrm{Ht}$ of $40 \%$ in the majority of patients. Therefore, to improve cost/effectiveness, the number of EPO injections should be related to baseline $\mathrm{Ht}$ instead of the four injections recommended in the product monograph.
Objectif : Évaluer le nombre d'injections d'érythropoïétine (EPO) nécessaires pour atteindre un hématocrite $(\mathrm{Ht})$ de $40 \%$ chez des patients modérément anémiques. Aussi, comparer cette stratégie avec le don de sang autologue (DSA) en chirurgie orthopédique réglée en termes de production de globules rouges (GR).

Méthode : Des patients ( $n=93)$ présentant un $\mathrm{Ht}$ de base de 30 à $39 \%$ ont été répartis en deux groupes le jour de l'évaluation préopératoire. Ceux du groupe EPO ont reçu 40,000 UI/semaine sc jusqu'à ce qu'ils présentent un Ht maximal de $40 \%$. Dans le groupe DSA, un culot globulaire a été prélevé chaque semaine tant que l'Ht était au-dessus de $33 \%$.

Résultats : II a fallu deux injections d'EPO pour atteindre un $\mathrm{Ht}$ de $40 \%$ chez $63 \%$ des patients. Il a été possible de prélever deux culots chez $45 \%$ des patients du groupe DSA. Le volume de production de GR a été significativement plus élevé chez ceux du groupe EPO : 268 $\pm 142 \mathrm{~mL}$ vs $141 \pm 129(P=0,000$ I). Dans le groupe EPO, l'Ht a été significativement plus élevé aux jours un et trois après l'opération et au moment du congé. Le score d'asthénie était moins prononcé dans le groupe EPO. Une transfusion allogénique a été faite chez 12,6\% des patients du groupe DSA vs 6,5\% du groupe EPO (ns).

Conclusion : II a suffi de deux injections d'EPO seulement pour atteindre un $\mathrm{Ht}$ de $40 \%$ chez la majorité des patients. Donc, pour améliorer l'efficacité des coûts, il faudrait relier le nombre d'injection d'EPO à l'Ht de base plutôt que de faire les quatre injections recommandées dans la monographie du produit.

From the Departments of Anesthesia, Paris M5 University - Cochin Hospital, ${ }^{*}$ Bichat University Hospital, $†$ Poitiers University Hospital, $\ddagger$ Reims University Hospital, $\$$ Paris; Avicenne University Hospital, $₫$ Bobigny, France.

Address correspondence to: Dr. Nadia Rosencher, Paris M5 University - Cochin Hospital, 27, rue du Faubourg St Jacques, 75014 Paris, France. Phone: 331584131 05; Fax: 3315841 14 96; E-mail: nadia.rosencher@cch.ap-hop-paris.fr

Financial support: Janssen-Cilag Laboratory.

Presented as an abstract at the ASA meeting in New Orleans, 2001.

Accepted for publication May 25, 2004.

Revision accepted November 5, 2004. 
A

UTOLOGOUS blood techniques have been developed mainly to prevent the risk of contamination by viruses (HVB, HCV and HIV). However, studies have demonstrated the high cost/effectiveness ratios related to autologous blood. ${ }^{1,2}$ The risk of allogeneic blood is now very small and the rigorous selection of blood donors has clearly contributed to improve the safety of allogeneic blood donations. Even if the immunosuppressive risk of leucocyte depleted blood remains controversial, large studies have shown that the rate of infections is higher with allogeneic blood transfusion. ${ }^{3-7}$ In addition, at this moment, there is an increasing scarcity of allogenic blood and major orthopedic procedures are delayed, due to allogeneic blood shortage. Recent data have demonstrated a possible risk for intraspecies transmission of bovine spongiform encephalopathy via blood. ${ }^{8}$ Recommendations issued from the French authorities have advised recently to: "limit the use of allogeneic red blood cells $(\mathrm{RBC})$ to only those indications for which the benefit is beyond doubt (life-threatening situation) and for which no therapeutic alternative is available; and whenever possible, resort to other alternatives such as autologous blood donation (ABD), human recombinant erythropoietin (EPO), cell salvage." The precautionary principle has thus pushed authorities to make unexpected recommendations and to promote alternative solutions.

According to the product monograph, four injections of EPO should be administered prior to elective surgery in moderately anemic patients. However, EPO entails a significant cost and four injections may not always be required.

The aim of this study was to assess the number of EPO injections necessary to reach a hematocrit $(\mathrm{Ht})$ of $40 \%$ in moderately anemic patients and, therefore, to find a less costly approach for the use of EPO. ABD and EPO are considered effective means of avoiding allogeneic transfusions and they have the same goal: to increase the available number of erythrocytes before the surgical procedure. Our secondary objective was to compare the use of EPO, in terms of efficacy, with a validated ABD strategy in elective orthopedic surgery.

\section{Patients and methods}

After Institutional Review Board approval and written informed consent, 100 patients whose Ht concentrations were between 30 and $39 \%$ were enrolled $30 \pm 9$ days before the scheduled intervention, in a prospective, multicentre $(n=16)$ and randomized study. The patients were followed for six weeks after surgery. Eligible patients were randomized into one of two treatment groups according to a randomization list generated by Janssen-Cilag. Randomization was centralized to avoid an imbalance of more than two patients between groups in each centre. Oral iron supplementation $\left(200 \mathrm{mg} \cdot \mathrm{day}^{-1}\right)$ was prescribed for all patients as of their inclusion. Starting three weeks before surgery [on day (D)-2l] and regardless of their body weight, patients in the EPO group received $s c 40$ $000 \mathrm{IU} /$ week of epoietin alfa (Eprex ${ }^{\circledR}$, Janssen-Cilag, France), until their Ht level reached $\geq 40 \%$. Patients in the ABD group had blood collected once a week, as long as the Ht level was $>33 \%$. The amount of blood loss was calculated by adding the red cell volume transfused, regardless of its origin (cell saving, autologous or allogenic), to the red cell volume lost between the day prior to surgery (D-1) and three days after $(\mathrm{D}+3) .{ }^{9,10}$

Total blood lost $=\mathrm{TBV} \times(\mathrm{Ht}$ at D-1 $-\mathrm{Ht}$ at D3 $)+$ (number of units of RBC transfused $\times 150 \mathrm{~mL}$ of $\mathrm{RBC})$

(where $\mathrm{TBV}=$ total blood volume $=$ body surface $\left(\mathrm{m}^{2}\right) \times$ constant, body surface $=0.0235 \times$ height $(\mathrm{cm})$ $0.42246 \times$ weight $(\mathrm{kg}) 0.51456$ and constant $=2,430$ for women, 2,530 for men)

The total amount of RBC produced was calculated as follows:

For the EPO group: RBC volume on D-1 minus $\mathrm{RBC}$ volume on D- 21;

For the ABD group: $\mathrm{RBC}$ volume withdrawn minus ( $\mathrm{RBC}$ volume on $\mathrm{D}-21$ minus $\mathrm{RBC}$ volume on D-1).

The decision to transfuse patients in either group was based on the recommendations of consensus conferences $^{11,12}$ i.e., Ht concentration between 21 and $30 \%$ according to the patient's medical history. The quality of life was assessed with visual analogue scales (VAS) $)^{13}$ at D-21, D-14, D-7 and D-1. Postoperative functional recovery was assessed with a questionnaire during the period $\mathrm{D}+1$ to $\mathrm{D}+15$. Safety was assessed by the frequency and the severity of adverse events, biological samples ( $\mathrm{Ht}$, hemoglobin, platelet count), and vital signs measured from the first consultation to visit $\mathrm{D}+30$. Specific questions about symptoms during the preoperative period (fatigue, headaches, malaise, nausea, palpitations and dyspnea) were asked.

Statistical analysis was conducted using the Chisquare test on the population defined by intention to treat (ITT). This analysis considered all the randomized patients who received either an injection of EPO or had blood collected for ABD. The per-protocol population is defined as all patients who strictly followed the protocol. Efficacy, postoperative recovery and tolerance parameters were analyzed by presenting values by visit, treatment group and patient, and by 
performing descriptive analyses by visit and treatment group. They were compared between treatment groups, with two-tailed tests performed with a level of significance 0.05 . Quantitative parameters (mean, standard deviation, minimum and maximum) were compared by Student $t$ test or Wilcoxon non-parametric test. Qualitative criteria (frequency and percentage per class) were analyzed by Chi-square test or Fisher's exact test. Between-group analyses were performed by Chi-square test or Fisher's exact test and Student $t$ test or Wilcoxon test. Analyses of variance on repeated measurements were used for Ht values. Ht variations from D-24 to D-1 were compared using a paired Student $t$ test on differences. VAS scores obtained at D-1, D-14 and D-7 on quality of life were analyzed by analysis of variance on repeated measurements, as well as vital signs and biological variables measured at D-21, D-1, D1, D3 and at discharge.

\section{Results}

Seven patients were excluded from all analyses after they withdrew their consent to participate or because of impossibility to perform $\mathrm{ABD}$ (hepatitis $\mathrm{C}$ ), leaving 93 patients in the ITT population. After exclusion or major violations of the protocol, 86 patients remained in the per-protocol population. The two groups did not differ significantly for any of the demographic variables (Table I). In the EPO group, the Ht threshold set at $40 \%$ was reached by $63.3 \%$ of the patients after one or two injections. After three EPO injections, $87.8 \%$ of the patients reached the Ht threshold (Figure 1).

In the $\mathrm{ABD}$ group, the volume of red cells withdrawn was $211 \pm 153 \mathrm{~mL}(\mathrm{Ht}=100 \%), 10 \%$ of the patients could not provide blood, $25 \%$ gave blood once, $45 \%$ were able to give blood twice and $20 \%$ were able to complete the protocol and give blood three times.

In the EPO group patients received a median number of two EPO injections (range 1-4). On the eve of the surgical procedure, the mean $\mathrm{Ht}$ value reached $44.4 \%$, even though no additional EPO injection was given after the $40 \%$ threshold had been reached. The Ht level evolution showed that the concentrations increased slowly (1.5\%) after the first injection, but much more quickly thereafter, reaching $6 \%$ after the third dose (Figure 2).

The amount of red cells produced was significantly higher in the EPO compared to the ABD group [268 $\mathrm{mL}$ vs $141 \mathrm{~mL}$, respectively, of $\mathrm{RBC}$ at $100 \% \mathrm{Ht}(P=$ $0.0001)]$. No difference in intra- and postoperative blood losses was found between the two groups. The mean \pm SD thresholds for allogeneic blood transfusions did not differ significantly between the groups
TABLE I Demographic and perioperative characteristics

\begin{tabular}{lll}
\hline Variable & $A B D(n=41)$ & $E P O(n=45)$ \\
\hline THR $(\%)$ & 84.4 & 85.4 \\
TKR $(\%)$ & 15.6 & 14.6 \\
Mean age \pm SD $(\mathrm{yr})$ & $63 \pm 13$ & $65 \pm 10$ \\
Female/male sex $(\%)$ & $87 / 13$ & $87 / 13$ \\
Arthrosis (\%) & 87 & 90 \\
Other diagnosis (\%) & 13 & 10 \\
Mean Ht day -30 \pm SD $(\%)$ & $37.6 \pm 2.1$ & $37.5 \pm 2.2$ \\
Mean Hb day $-30 \pm S D\left(\mathrm{~g} \cdot \mathrm{dL}^{-1}\right)$ & $12.4 \pm 0.6$ & $12.3 \pm 0.6$ \\
\hline
\end{tabular}

$\mathrm{ABD}=$ autologous blood donation; $\mathrm{EPO}=$ epoetin-alfa; $\mathrm{THR}=$ total hip replacement; TKR = total knee replacement; $\mathrm{Ht}=$ hematocrit; $\mathrm{Hb}=$ hemoglobin. No significant difference.

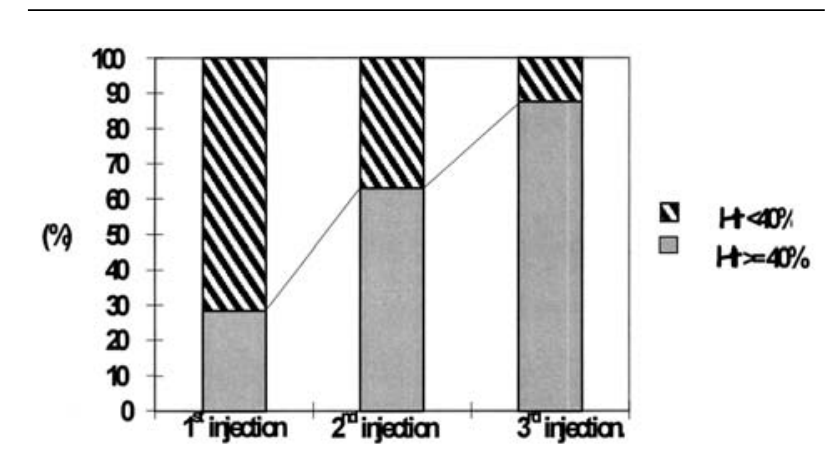

FIGURE 1 Evolution of the hematocrit in the erythropoietin group. $P<0.05$ between groups from D-7 to D-out.

$(21.6 \pm 6.9 \% \mathrm{Ht}$ for $\mathrm{ABD}$ ps $20.7 \pm 4.2 \% \mathrm{Ht}$ for $\mathrm{EPO})$. The number of transfused patients and the number of packed RBC units transfused (autologous and allogeneic blood) were significantly higher in the ABD group $(P=0.0001) .6 .6 \%$ of the EPO group and $12.6 \%$ of the ABD group received allogeneic blood $P$ $=$ ns $($ Table II). In the EPO group, the Ht was significantly higher on $\mathrm{D}+1$ and +3 and at discharge. Finally, daily activity, quality of life and energy score, as assessed by the VAS throughout the study, were rated significantly better two weeks before the intervention by patients who had received EPO (Table III). There was no significant difference between groups for the occurrence of treatment-related adverse events (Fisher's exact test: $P=0.32$ ), treatment discontinuation (Fisher's exact test: $P=0.45$ ) and the occurrence of serious adverse events (Fisher's exact test: $P=1.000$ ). 
TABLE II Secondary outcome variables

\begin{tabular}{|c|c|c|c|}
\hline Variable & $A B D(n=41)$ & $E P O(n=45)$ & $P$ \\
\hline Allogenic transfusions (number of units) & 6 & 3 & NS \\
\hline Patients transfused allogeneic blood (\%) & 12.6 & 6.6 & NS \\
\hline \multicolumn{4}{|l|}{ Blood loss ( $m L$ of $R B C$ ) } \\
\hline at $100 \% \mathrm{Ht}$ & $466 \pm 252$ & $562 \pm 298$ & NS \\
\hline at $35 \% \mathrm{Ht}$ & $1345 \pm 720$ & $1605 \pm 850$ & NS \\
\hline Volume of red cells produced $(\mathrm{mL})$ & $141 \pm 129$ & $268 \pm 142$ & 0.0001 \\
\hline \multicolumn{4}{|l|}{ Mean $H t \pm S D$} \\
\hline day $-30(\%)$ & $37 \pm 2$ & $37 \pm 2$ & NS \\
\hline day $-1(\%)$ & $35 \pm 3$ & $44 \pm 2$ & 0.0001 \\
\hline day $+1(\%)$ & $28 \pm 4$ & $34 \pm 5$ & 0.0001 \\
\hline day $+3(\%)$ & $30 \pm 4$ & $33 \pm 5$ & 0.02 \\
\hline day of discharge (\%) & $32 \pm 3$ & $34 \pm 4$ & 0.02 \\
\hline $\mathrm{Hb}$ threshold for allotransfusion $\left(\mathrm{g} \cdot \mathrm{dL} \mathrm{L}^{-1}\right)$ & $7.2 \pm 2.3$ & $6.9 \pm 1.4$ & NS \\
\hline \multicolumn{4}{|c|}{ Self-assessed visual analogue scale scores (mean $\pm S D / 100)$} \\
\hline Daily activity & $56 \pm 28$ & $71 \pm 19$ & 0.005 \\
\hline Quality of life & $57 \pm 25$ & $72 \pm 20$ & 0.004 \\
\hline
\end{tabular}

$\mathrm{ABD}=$ autologous blood donation; $\mathrm{EPO}=$ erythropoietin; $\mathrm{RBC}=$ red blood cells; $\mathrm{Ht}=$ hematocrit; $\mathrm{Hb}=$ hemoglobin.

TABLE III Postoperative functional recovery (in days; per protocol population)

\begin{tabular}{llll}
\hline Recovery/group & EPO & ABD & P value \\
\hline Exhausted (days) & $0.6 \pm 0.9$ & $1.34 \pm 2.49$ & 0.18 \\
Out of breath (days) & $0.45 \pm 1.59$ & $0.53 \pm 1.56$ & 0.95 \\
Vertigo/malaise (days) & $1.25 \pm 1.87$ & $1.24 \pm 1.57$ & 0.78 \\
Re-education exercises (days) & $2.57 \pm 3.93$ & $3.00 \pm 3.60$ & 0.51 \\
Breathing exercises (days) & $0.61 \pm 1.66$ & $0.54 \pm 1.87$ & 0.39 \\
Help to wash (days) & $1.98 \pm 2.03$ & $2.78 \pm 2.04$ & 0.0525 \\
Help to dress (days) & $2.74 \pm 2.54$ & $2.94 \pm 2.50$ & 0.54 \\
Able to sit down in armchair (days) & $5.48 \pm 2.71$ & $6.30 \pm 3.48$ & 0.56 \\
Able to walk in the bedroom (days) & $6.65 \pm 3.11$ & $7.10 \pm 3.27$ & 0.80 \\
\hline
\end{tabular}

$\mathrm{EPO}=$ erythropoietin; $\mathrm{ABD}=$ autologous blood donation.

\section{Discussion}

We have shown that a limited number of EPO injections (one or two) is sufficient to reach a preset $40 \%$ Ht in $63 \%$ of patients. In fact, Ht reached $44 \%$ the day prior to surgery in patients who received EPO without any further injection. Many studies have demonstrated the efficacy of EPO as an alternative to allogeneic blood transfusion. The meta-analysis conducted by Laupacis and Fergusson confirmed this efficacy. ${ }^{14}$ However, no study to date has defined the optimal number of EPO injections according to baseline Ht. Indeed, the amount of red cells generated during the preoperative period enables the patient to avoid, or at least to decrease, the need for allogeneic blood transfusion. EPO labelling, in Europe, proposes the same number (four) of injections for all patients, regardless of $\mathrm{Ht}$ level, when the $\mathrm{Ht}$ lies between $30 \%$ and $39 \%$. Physicians are concerned by the cost of EPO and this is why they tend to use $\mathrm{ABD}$ in moderately anemic patients even if this strategy is marginally effective.

Our study confirms that red cell production persists even after stopping the injections of EPO. ${ }^{15}$ This mechanism explains why the Ht concentration continues to rise in the absence of further injections when iron supplementation is adequate. The risk of reaching a Ht level $>45 \%$ after three injections prior to surgery does exist if the $\mathrm{Ht}$ is not monitored and this risk is anticipated by the monograph of the product. Indeed, it is not allowed to continue EPO if the $\mathrm{Ht}$ is $\geq 45 \%$. With increasing $\mathrm{Ht}$, blood viscosity increases and a thrombotic risk in this elderly population could exist. ${ }^{16}$ According to our results, starting the first injection of EPO four weeks before surgery appears to be an efficient approach since $\mathrm{Ht}$ levels will continue to rise. However, no general rule can be applied to all patients: the lower the Ht concentration on day -30 , 


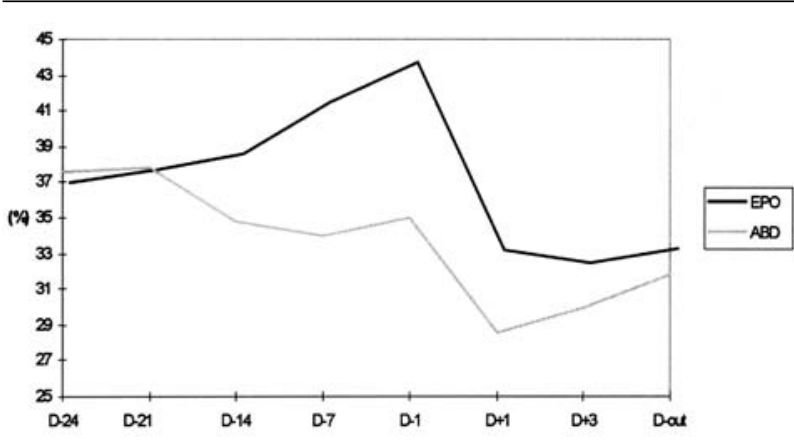

FIGURE 2 Evolution of the hematocrit in the erythropoietin and autologous blood donation groups.

the higher the number of EPO injections may be to reach the desired threshold. In our study, the mean baseline Ht level was $36.9 \%$, explaining why two injections were sufficient for $63.3 \%$ of the patients. Evolution of the $\mathrm{Ht}$ showed that $\mathrm{Ht}$ increased slowly after the first EPO injection: $1.5 \% \mathrm{Ht}$ after the first week but much more quickly thereafter, reaching $6 \%$ $\mathrm{Ht}$ as of the third dose, in agreement with the literature. Thus, on average, $\mathrm{Ht}$ progresses by $2 \%$ per week and per EPO injection. ${ }^{15-17}$ In moderately anemic patients, the number of autologous units collected is limited, and thus the mass of erythrocytes withdrawn and regenerated is also reduced. The initially moderate anemia in the ABD group worsened with each withdrawal of blood, whereas anemia progressively regressed in patients who received EPO.

Allogeneic transfusion requirements were not different between groups but the study was not powered adequately to detect such differences, 370 patients per group would have been required to detect a difference with $80 \%$ power. Allogeneic blood was transfused at the same Ht level $(21.6 \%)$ in both groups. In both groups patients who required allogeneic transfusions needed between three and six units of packed RBC, attesting to particularly high blood losses. The number of RBC units transfused was significantly higher in the $\mathrm{ABD}$ group, probably because of anemia at the time of surgery. However, even if autologous RBC represented $80 \%$ of the transfusions, the risks inherent to autologous transfusions do exist at the time of surgery. Indeed, the risks of clerical errors or the mistransfusion rate (blood transfused to other than the intended recipient) has been estimated to be one in 14,000 units in the United States and one in 18,000 in the United Kingdom. ${ }^{18,19}$ A similar error rate (one in 17,000) has been identified for autologous blood units in Canada. One in 33,000 units is ABO incompatible because of error, one half of those are associated with a transfusion reaction, and approximately $10 \%$ are fatal. Furthermore ABD does not eliminate the risk of bacterial contamination. ${ }^{20}$

Daily activity, the quality of life and energy score, as assessed by the VAS throughout the study, were rated significantly better at approximately two weeks before surgery by patients who had received EPO. It is appealing to correlate the $\mathrm{Ht}$ level to quality of life and energy scores as it has already been demonstrated in renal insufficiency and after chemotherapy. ${ }^{21-25}$ Furthermore, Ht on the day following surgery and on the day of discharge were significantly higher in the EPO than in the ABD group. Assessment of early postoperative recovery, (vigour and functional ability) in surgical patients is considered to be important for optimizing patient rehabilitation, discharge planning and health system resource utilization. In his study, Keating demonstrated ${ }^{26}$ that the postoperative $\mathrm{Ht}$ level is correlated strongly with muscle strength, as is postoperative patient "well-being." However, variables of postoperative functional recovery were not different between groups in our study.

In summary, we believe that it is essential to adapt the transfusion strategy to each patient according to his/her erythrocyte volume and predicted total blood loss. This strategy should be applied to the use of $\mathrm{EPO}$, according to each patient's baseline $\mathrm{Ht}$, regardless of the monograph of the product. It appears also that patient well-being and readiness to resume normal activities should be taken into account when planning transfusion strategies.

\section{Acknowledgements}

Pr. Jean François Baron member of the Steering Committee and of the investigators involved in this study: A. Albi, A. Belbachir, L. Eyrolle (Hôpital Cochin, Paris), C. M. Samama (Hôpital Avicenne, Bobigny), M. Aperce (CHU, Poitiers), Y. Hemon (Hôpital Dte Marguerite CHU, Marseille), E. LePelley (Clinique de la Providence, Poitiers), J. J. Pinson, D. Leguen, E. Leberre (Polyclinique de l'Atlantique, St Herbelain), D. Envain (Institut Calot, Berck), J. M. Debue (Clinique des Maussins, Paris), C. Claquin (Kremlin, Bicêtre), A. Pellefigue (Clinique La Garenne, Dracy), R. Normand (CHG, Annecy), A. Simon (Hôpital st Antoine, Paris), D. Haro (Clinique mutualiste, Lyon), X. Capdevila (Hôpital Lapeyronnie, Montpellier). 


\section{References}

1 Etchason J, Petz L, Keeler E, et al. The cost effectiveness of preoperative autologous blood donations. N Engl J Med 1995; 332: 719-24.

2 Birkmeyer JD, Goodnough LT, AuBuchon JP, Noordsij $P G$, Littenberg $B$. The cost-effectiveness of preoperative autologous blood donation for total hip and knee replacement. Transfusion 1993; 33: 544-51.

3 Borghi B, Casati A. Incidence and risk factors for allogenic blood transfusion during major joint replacement using an integrated autotransfusion regimen. The Rizzoli Study Group on Orthopaedic Anaesthesia. Eur J Anaesthesiol 2000; 17: 411-7.

4 Innerhofer P, Walleczek C, Luz G, et al. Transfusion of buffy coat-depleted blood components and risk of postoperative infection in orthopedic patients. Transfusion 1999; 39: 625-32.

5 Bierbaum BE, Callaghan JJ, Galante JO, Rubash HE, Tooms RE, Welch RB. An analysis of blood management in patients having a total hip or knee arthroplasty. J Bone Joint Surg Am 1999; 81: 2-10.

6 Rosencher N, Kerkkamp HE, Macheras G, et al. Orthopedic surgery transfusion hemoglobin European overview (OSTHEO) study: blood management in elective knee and hip arthroplasty in Europe. Transfusion 2003; 43: 459-69.

7 Murphy P, Heal JM, Blumberg N. Infection or suspected infection after hip replacement surgery with autologous or homologous blood transfusions. Transfusion $1991 ; 31: 212-7$.

8 Houston F, Foster JD, Chong A, Hunter N, Bostock CJ. Transmission of BSE by blood transfusion in sheep. Lancet 2000; 356: 999-1000.

9 Mercuriali F, Inghilleri $G$. Proposal of an algorithm to help the choice of the best transfusion strategy. Curr Med Res Opin 1996; 13: 465-78.

10 Brecher ME, Rosenfeld M. Mathemetical and computer modeling of acute normovolemic hemodilution. Transfusion 1994; 34: 176-9.

11 Société Française d'anesthésie et de réanimation. Utilisation des globules rouges pour la compensation des pertes sanguines en chirurgie de l'adulte. Conférence de consensus. Ann Fr Anesth Réanim 1995; 14(Suppl 1): 1-117.

12 American College of Physicians. Practice strategies for elective red blood cell transfusion. Ann Intern Med 1992; 116: 403-6.

13 Priestman TJ, Baum M. Evaluation of quality of life in patients receiving treatment for advanced breast cancer. Lancet 1976; 24: 899-901.

14 Laupacis A, Fergusson D. Erythropoietin to minimize perioperative blood transfusion: a systematic review of randomized trials. The International Study of Peri- operative Transfusion (ISPOT) Investigators. Transfus Med 1998; 8: 309-17.

15 Goodnough LT, Monk TG, Andriole GL. Erythropoietin therapy. N Engl J Med 1997; 336: 933-8.

16 Small M, Lowe GD, Cameron E, Forbes CD. Contribution of the haematocrit to the bleeding time. Haemostasis 1983; 13: 379-84.

17 Mercuriali F. Epoetin alfa increases the volume of autologous blood donated by patients scheduled to undergo orthopedic surgery. Semin Hematol 1996; 33(Suppl 2): 10-2.

18 Goodnough LT. Autologous blood donation. Crit Care 2004; 8(Suppl 2): S49-52.

19 Goodnough LT. Risks of blood transfusion. Crit Care Med 2003; 31(Suppl): S678-86.

20 Goodnough LT, Brecher ME, Kanter MH, AuBuchon JP. Transfusion medcine. Second of two parts. Blood conservation. N Engl J Med 1999; 340: 525-33.

21 Weiskopf RB, Feiner J, Hopf HW, et al. Oxygen reverses deficits of cognitive function and memory and increased heart rate induced by acute severe isovolemic anemia. Anesthesiology 2002; 96: 871-7.

22 Watanabe A, Kato N, Kato T. Effects of creatine on mental fatigue and cerebral hemoglobin oxygenation. Neurosci Res 2002; 42: 279-85.

23 Sobrero A, Puglisi F, Guglielmi A, et al. Fatigue: a main component of anemia symptomatology. Semin Oncol 2001; 28(Suppl 8): 15-8.

24 Gabrilove JL, Cleeland CS, Livingston RB, Sarokban B, Winer E, Einhorn LH. Clinical evaluation of onceweekly dosing of epoetin alfa in chemotherapy patients: improvements in hemoglobin and quality of life are similar to three-times-weekly dosing. J Clin Oncol 2001; 19: 2875-82.

25 Littlewood TJ, Bajetta E, Nortier JW, Vercammen E, Rapoport B; Epoetin Alfa Study Group. Effects of epoetin alfa on hematologic parameters and quality of life in cancer patients receiving nonplatinum chemotherapy: results of a randomized, double-blind, placebo-controlled trial. J Clin Oncol 2001; 19: 2865-74.

26 Keating EM, Ranawat CS, Cats-Baril W. Assessment of postoperative vigor in patients undergoing elective total joint arthroplasty: a concise patient- and caregiver-based instrument. Orthopedics 1999; 22(1 Suppl): s119-s28. 